\title{
GREAT CRESTED FLYCATCHER
}

JEAN BANCROFT, 306 - 200 Tuxedo Avenue, Winnipeg, Manitoba. R3P OR3

For the past several summers a pair of Great Crested Flycatchers has nested somewhere in the immediate area of our cottage at Whytewold (in the southwest corner of Lake Winnipeg), but I had not been able to find the nesting site. ${ }^{1}$

Hoping to attract this species to our yard, in the spring of 1981 my husband built a nesting box which was attached to an old poplar tree at the edge of the wooded area on our property. The box had a gabled roof and measured $28 \mathrm{~cm}$ by $16 \mathrm{~cm}$ by $15 \mathrm{~cm}$ with an opening ( 5 $\mathrm{cm}$ in diameter) situated $6.2 \mathrm{~cm}$ from the top of the box. The stoop was placed $2.5 \mathrm{~cm}$ below the opening. The box was $3 \mathrm{~m}$ from the ground and close to one side stood a tall thin ash and Saskatoon bush. The foliage gradually spread out so that some leaves of the ash obscured part of the opening from my view.

After the erection of the box I naturally looked and listened for the arrival of these bir'ds in our area. Sure enough, on 31 May, I heard their raucous calls down the lane. I loitered around, hoping that the birds would come into our yard and maybe, just maybe, might see our white nesting box. Lo and behold, that is just what happened a couple of days later. I was so excited that I could hardly contain myself and ran to tell my husband that the birds were examining the box. They looked around it and went in and out then flew away. It wasn't until 6 June that they finally chose our box for their nesting site.

As both sexes appear identical in appearance it was difficult to determine if both the male and female took part in the nest building. However, it appeared to me that the male gave most of the shrieking calls when chasing after the female during the time she scoured the immediate area for suitable materials. They were always together and the loud "kweep" and the "wick-wick-wicks" could be heard over a block away.

It was extremely interesting to watch the bird when it was taking materials into the box. It never went directly to the hole but always sat on one of the bare poplar branches behind the box. Then it sneaked around the corner, as it were, passing under a leafy branch of the slim ash tree, and entered the box. When coming out it did so cautiously, looked all around, then dipped lower down into some hazelnut bushes, before flying away.

As is the usual procedure for flycatchers, both male and female performed aerial acrobatics to catch insects, and invariably perched on the bare branches of surrounding trees. The same procedure was followed when they fed the nestlings.

If a Red or Grey Squirrel ran up and down a tree close to the nesting site both sexes would attack it. There was a pair of wrens nesting in a little box hanging from a nearby oak tree, and the Great Crested Flycatchers saw to it that the little wrens did not dare venture close to the old poplar. Also, later on I noticed that a male oriole and a robin, in need of food for their young, began to pick Saskatoon berries off the bush close to the nestbox and both sexes flew at them. It amused me to see, however, that they did not use this aggressive behaviour towards a fledged oriole when the parent left it on the Saskatoon bush for a couple of hours. 


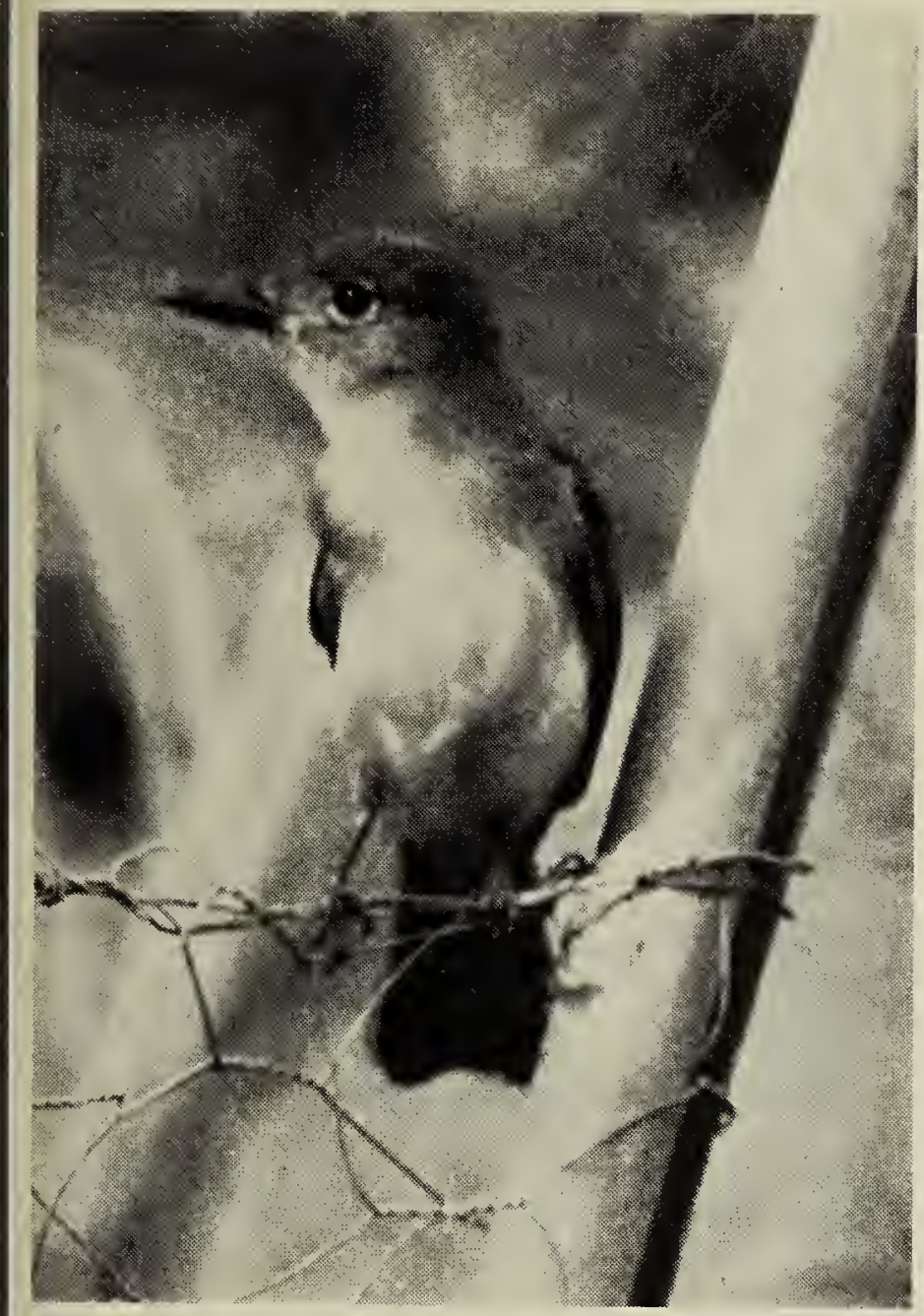

Great Crested Flycatcher.

Sheina Wait

I believe incubation commenced about 15 June but I could not determine whether both male and female participated in this process. Even the experts do not seem to agree on this point. ${ }^{2}{ }^{3} \mathrm{On}$ many occasions an adult would come out and the other bird would give the loud call; then both adults flew around the treetops and one would enter the box, but whether it was always the female I cannot say.

On 28 June I noticed one adult darting around for insects and then it sat on a bare branch, but I was not able to see if either adult was carrying food into the box. The incubation period evidently takes from 13 to 15 days so I therefore watched more closely. ${ }^{2}{ }^{3}$ On 29 June I noticed an adult enter the box, turning its head sideways and backwards before it did so. But it was not until 4 July that I was able to establish that both adults tended the nestlings. Both adopted the same procedures. After catching an insect they did not fly direct- ly to the nestbox but perched on a bare limb first, dipped down into the bushes and then flew to the box, usually perching on the rim of the hole and very rarely using the stoop.

During each of the next 3 days I paid particular attention to the parents' activities from approximately 1600 to 1715. On 6 July I observed the adults make eight trips to the box with various insects, including fishflies, midges, housefly, Painted Lady butterfly, and what appeared to be a small beetle. On several occasions droppings were brought out, at which time the adults flew many feet away for disposal. At all times I noticed that both birds were extremely wary of the slightest sound made by other birds, squirrels, and/or other intruders.

On 11 July I realized that the nestlings were nearing maturity; during feeding times more of the adult's body protruded from the hole.

On 14 July, in addition to casual observations, I managed to observe from 1540 until 1710. At 1540 one young head protruded from the hole and then drew back in, but at 1700 the fledgling came half way out. When food was brought I could see young ones in the box bobbing up and down, but I was not able to determine the number.

Unfortunately, I was not able to be at the cottage again until noon on the 17 at which time I found the nestbox deserted. I was very sorry that I had missed the exciting climax to the nesting period. Due to unforeseen circumstances it was necessary for us to leave the cottage on the 18 for some weeks. Before leaving, my husband took down the box and carefully unscrewed the bottom.

I shall endeavour to describe in detail the interesting nest which came out intact. There was a thin base of twigs, then approximately $10 \mathrm{~cm}$ of peat moss gathered from our wooded lot. To the left of centre was the small cup for the 
eggs and in this were feather scales and three cold eggs which I presume had been infertile. There can be as many as eight altogether. ${ }^{2}{ }^{3}$ These eggs were light buffy in colour and were "blotched, lined and streaked with browns."2 Two appeared to be identical but one was different in that it had "some scratches or fine hairlines." ${ }^{3}$ In the left-hand corner of the nest was a clump of skunk fur, and in the right-hand corner was a small white wing of a bird. There were some other feathers and plant fibres arranged around the edges of the nest.

Although I was not able to be on hand to see the fledglings leave the nestbox, I feel that the nesting was a success due to the fact that, from my observations, the fledglings were well matured; there were feather scales in the nesting cup,

\section{OWL BANDING ASSISTED BY SASKATCHEWAN POWER CORPORATION}

MARY ZELDIN, Information Services Dept., S.P.C., 2025 Victoria Ave., Regina, Saskatchewan. S4P 0S1

In May 1981 a routine air patrol of the electrical transmission tower line just east of Saskatoon turned up the highest great horned owl nest ever found in Saskatchewan.

The former hawk's nest on tower number 377 was home to a mother owl, one of her young, and an unhatched egg, when spotted by Peter Sielski, journeyman/lineman at the Queen Elizabeth power station in Saskatoon.

"We knew of the nest last year when it was empty, but seeing the owls there prompted us to call someone who knew about birds," Pete said in an interview in Saskatoon this summer. and there were many small droppings on the top of the box and down the back of it, as well as on the wires which held the box to the tree.

I observed many nesting boxes during the summer of 1981 but no nesting gave me greater enjoyment and satisfaction than the Great Crested Flycatchers'.

'BANCROFT, JEAN. 1981. Flycatcher Family. Blue Jay 39(2): 104-106.

${ }^{2}$ GODFREY, W. E. 1966. The birds of Canada. Nat. Mus. Canada Bull. 203. Ottawa. 428 pp.

${ }^{3}$ HARRISON, H. H. 1975. A field guide to birds' nests in the United States east of the Mississippi River. Houghton Mifflin, Boston. 257 pp.

The expert called in was radiologist Stuart Houston. Dr. Houston is highly regarded both among ornithologists and the farmers and Saskatchewan Power Corporation (SPC) workers he and his wife Mary meet on bird banding trips. He was excited to hear about the owls on the $36.5 \mathrm{~m}$ steel tower. "Great horned owls are not rare in Saskatchewan but their nests are usually not as high as the one on the power pole, 70 feet $(21.3$ m) up. That's the highest we've ever found," he said in a telephone interview in September.

"SPC is responsible for us finding some of these birds; the towers are convenient for nest building," said Dr. Houston. "No owl makes its own nest," he said. In this case a Red-tailed Hawk made the nest in 1979 .

On 12 May the young owl was banded as was another young bird rescued from starvation after being found homeless in Manitoba, and placed in the nest to replace the infertile egg that 